*Mestrado em Ciências Jurídicas pela UNICESUMAR. Especialista em Direito e Prática Previdênciária pela Pontifícia Universidade Católica do Paraná (PUCPR). Especialista em Direito de Família e Sucessões pelo Damásio Educacional. Especialista em Direito do Trabalho e Direito Previdenciário pelo Instituto de Direito Constitucional e Cidadania (IDCC). Graduação em andamento em Licenciatura de Letras Português/Inglês pela UNICESUMAR. Graduada em Direito pela Pontifícia Universidade Católica do Paraná (PUCPR)

Email: anapaulabatista_@hotmail. com

* Pós Doutora pela Faculdade de Direito da Universidade de Lisboa. Doutora em Direito pela Pontifícia Universidade Católica de São Paulo (PUCSP). Mestre em Direito pela Pontifícia Universidade Católica de São Paulo (PUCSP). Graduada em Direito pela Univesidade Estadual de Maringá.

Email: lemead@uol.com.br

\section{A REVISTA Í́ntima no Meio Ambiente de Trabalho e a Violação da dignidade da Pessoa Humana à Luz da InTEligênCIA Artificial e dos Aspectos TeCnOLógicos}

\author{
Close InsPections In THE WORKPLACE AND THE \\ VIOLATION OF THE DIGNITY OF THE HUMAN PERSON FROM \\ THE PERSPECTIVE OF ARTIFICIAL INTELLIGENCE AND \\ TECHNOLOGICAL ADVANCES
}

Ana Paula Baptista Marques*
Leda Maria Messias da Silva**

Como Citar: MARQUES, Ana Paula Baptista. DA SILVA, Leda Maria Messias. A revista intima no meio ambiente de trabalho e a violação da dignidade da pessoa humana à luz da inteligência artificial e dos aspectos tecnológicos.Scientia Iuris, Londrina, v.24, n.1, p. 135-148, março 2020. DOI $10.5433 / 21788189.2020 \mathrm{v} 24 \mathrm{n} 1 \mathrm{p} 135$. ISSN 2178-8189.

Resumo: Este artigo concentra-se na análise dos Direitos e Garantias Fundamentais que regulam a vida social, política e jurídica dos cidadãos brasileiros, acrescidos dos princípios constitucionais, que garantem à pluralidade, inclusive aos trabalhadores, especialmente a dignidade da pessoa humana. Nesse sentido, num primeiro momento, este estudo propõe-se a ponderar as revistas que os empregadores ou seus prepostos realizam nos empregados, quando da vigência do contrato de trabalho a fim de observar, igualmente, quando há abuso do poder diretivo do empregador e, quais são os direitos personalíssimos lesados dos trabalhadores. Para exemplificar esse contexto, no segundo tópico, o artigo analisa a nova conjuntura marcada por sucessivos e significativos avanços tecnológicos e pelo advento de máquinas direcionadas ao monitoramento desses empregados, com o intuito de evitar que tais sejam submetidos às revistas íntimas, especialmente ao contato físico, comumente constrangedor, e, por fim, este estudo tece um paralelo entre o atual progresso da automação nos postos de trabalho e a chegada da inteligência artificial na seara trabalhista enquanto forte aliada para os progressos dentro dos espaços empresariais. Para fundamentação do exame proposto, o método utilizado é o indutivo, que, mediante observação de questões particulares, 
enseja a extração de conclusões mais abrangentes.

Palavras chave: Revista íntima. Inteligência artificial. Dignidade humana.

\begin{abstract}
This scientific article analyzes fundamental rights and guarantees that regulate social, political and legal aspects of Brazilian citizens lives. In particular, this paper explores constitutional principles that guarantee workplace diversity - specifically, a right stemming from the dignity of the human person. In this sense, this study initially questions whether stopping and frisking employees is an abuse of the employer's directive power and, therefore, violates an employee's contract. In order to better illustrate this context, this paper also analyzes the successive and significant technological advances of the twenty first century, which, with the advent of machines, have been used to monitor employees, in order to prevent them from being stopped and frisked - a practice which can be significantly embarrassing for the employee. Finally, this research draws a parallel between the current progress of automation in the workplace and the arrival of artificial intelligence in the labor market as a strong ally for progress within business spaces. In order to reach our conclusions, this study utilized the inductive method with the use of comprehensive scientific observations.
\end{abstract}

Keywords: Intimate magazine. Artificial Intelligence. Human dignity. 


\section{INTRODUÇÃO}

Em 1988, a Constituição brasileira legitimou, em seu art. $5^{\circ}$, a igualdade a todos perante a Lei, garantindo aos brasileiros, e também aos estrangeiros residentes no país, a inviolabilidade do direito à vida (digna), à honra, à imagem e à intimidade e vida privada (BRASIL, 1988). Tal dispositivo, portanto, deu azo aos direitos constitucionais que, por seu turno, foram, individualmente, conceituados e alargados aos princípios e às garantias fundamentais, dentre os quais o destaque está na dignidade da pessoa humana.

É sob esse enquadramento, então, que o presente estudo expõe os direitos fundamentais, constitucionalmente previstos, bem como suas conquistas na década de noventa com a Constituição Cidadã, com a oficialização dos direitos e das garantias a todos os indivíduos, sem distinção de qualquer natureza, sendo todos abarcados de igual modo, até mesmo os estrangeiros.

Assim, doravante interpretações teleológicas, esta análise tem na filosofia kantiana o fulcro necessário para elucidar que a dignidade da pessoa humana emergiu anteriormente ao Estado, caracterizando-se enquanto um princípio basilar dos direitos fundamentais.

Ademais, considerada a amplitude da Constituição Federal de 88 no amparo às condições humanas, entra em cena, por um viés controvertido, o tema da revista íntima praticada por empregadores no meio ambiente de trabalho, ação em geral abusiva, cujo alcance pode acarretar danos morais a serem reparados aos trabalhadores.

Por conseguinte, acurada a questão, este estudo se aprofundará, particularmente, no exame do direito à intimidade e à vida privada do trabalhador, intentando demonstrar a extrema relevância dos direitos fundamentais, especialmente dos trabalhadores, tendo em vista o fato de que mais grave do que ofender uma norma é violar um princípio, uma vez que aquela é o corpo material, ao passo que este é o espírito, a alma que dá vida à lei.

Nesse diapasão, em função da revista íntima dos empregadores e seus prepostos aos funcionários, serão evidenciados os direitos fundamentais e as garantias constitucionais, cuidando para que sejam priorizados e observados pelo empresariado, no ato da revista de seus empregados, evitando-se constrangimentos, abusos de poder ou o desrespeito aos direitos previstos na Lei Maior.

Reconhecendo a importância dos direitos fundamentais e da dignidade humana do trabalhador, haja vista a inviolabilidade da intimidade e da vida privada do empregado, esta exposição aponta que a vistoria íntima é abusiva, pois rompe, diretamente, com a dignidade da pessoa humana.

Não existe revista íntima razoável. Nessa toada, o estudo em apreço demonstra que já se multiplicam diversos entendimentos jurisprudenciais que consideram o ato em si um abuso de direito e, diante do regramento constitucional, como algo ilícito.

À vista disso, para que sejam realizadas revistas nos empregados, já que essas são legalmente permitidas pela legislação trabalhista, os trabalhadores revistados deveriam ser submetidos, por exemplo, a equipamentos eletrônicos, tendo em conta que os avanços tecnológicos caminham de 
braços dados com o desenvolvimento atual dos postos de trabalho, destinando-se, essencialmente, à prevenção de constrangimentos desnecessários e ofensas à dignidade da pessoa humana.

Em semelhante medida, admite-se que, futuramente, com o aperfeiçoamento da inteligência artificial nos postos de trabalho, as revistas realizadas pelos empregadores em seus funcionários sejam robotizadas, afinal os benefícios desta inovação são inúmeros, dentre eles: a diminuição da jornada de trabalho e, também, a substituição da ação humana ou, em outras palavras, do constrangedor contato físico.

O método adotado é o indutivo, o qual parte de questões particulares para as gerais.

\section{DOS DIREITOS FUNDAMENTAIS E DA DIGNIDADE DA PESSOA HUMANA}

São considerados essenciais todos os direitos que tornam indissociáveis a relação entre o princípio da dignidade humana e os direitos fundamentais.

Dessa relação, surgiram os direitos individuais e coletivos, previstos e pacificados em título próprio, dos direitos e das garantias da $\mathrm{CF} / 88$. Ambos estão, umbilicalmente, ligados ao conceito de pessoa humana e à sua personalidade, a saber: à igualdade, à dignidade humana, à intimidade e vida privada, previstos no art. $5^{\circ}$ e incisos do mesmo corpo jurídico.

Ressalta o texto constitucional que os destinatários desses direitos são todos os brasileiros e estrangeiros residentes no país, além dos apátridas, isto é, pessoas jurídicas e estrangeiros que não residem no país, sendo esses últimos inclusos pela interpretação sistemática e teleológica do artigo em lume, o qual anuncia que todos são iguais, sem distinção de qualquer natureza, independentemente de sua nacionalidade ou situação no país (BRASIL, 1988).

Sob essa ótica, pondera-se que toda pessoa é titular dos direitos fundamentais, que, de sua parte, nascem com o indivíduo e, por isso, não representam uma concessão do Estado.

É aqui que se encontra inserido o princípio da dignidade humana enunciado por Kant como fórmula do imperativo categórico para que todo ser humano trate a humanidade, tanto na sua própria pessoa como na pessoa de todo outro, sempre como um fim e nunca unicamente como um meio, pois todo ser racional, como fim em si mesmo, possui um valor intrínseco: a dignidade (KANT, 1974, p. 20).

Com base nesse princípio da dignidade da pessoa humana, constata-se que toda e qualquer pessoa têm assegurados os direitos fundamentais, constitucionalmente previstos, os quais, por sua natureza basilar, garantem a todos serem seus titulares. Dentre esses direitos, estão o direito à vida, à honra, à intimidade e à vida privada; e, notadamente amparado por esta investigação, o direito dos trabalhadores.

A expressão direitos fundamentais do homem não significa, portanto, esfera privada contraposta à atividade pública, como simples limitação do Estado, remetendo, antes, à restrição imposta pela soberania popular aos poderes constituídos do Estado que dela dependem (ALEXY, 2008, p. 10). Logo, esses direitos traduzem os bens da vida, à medida que as garantias almejam assegurá-los. Nesse ponto participa a dignidade dos trabalhadores, isso porque o labor faz parte da 
própria história da existência humana, ressaltando que os valores sociais do trabalho e a dignidade são fundamentos constitucionalmente consagrados na Carta Magna.

Congregando os direitos fundamentais do homem e, especificamente, os direitos sociais e os princípios que lhe são próprios, denota-se que todos são imprescindíveis à concretização da própria dignidade da pessoa humana. Isso posto, José Afonso da Silva defende que os direitos sociais constituem, categoricamente, os novos direitos fundamentais do homem, à proporção que espelham um meio positivo que reconhece o direito ao trabalho como condição precípua no caminho da efetividade da existência digna de todos os brasileiros (SILVA, 2007, p. 45).

Ocorre que, embora a justiça social seja constitucionalmente garantida, mediante o valor social ao trabalho digno para todos, desde a Revolução Industrial, com a adoção do capitalismo, os direitos sociais para todos enfrentam obstáculos ante as evidentes desigualdades sociais desse modelo econômico.

Com o intuito de solucionar tais divergências, desponta a flexibilização, que, de outro modo, pode ser entendida como a exclusão dos direitos trabalhistas, visto que tal prática não parece ser um instrumento apto a reequilibrar a posição de inferioridade com que se depara a massa de trabalhadores brasileiros e em virtude da qual esses se veem impedidos do efetivo exercício das liberdades constitucionalmente garantidas (SARLET, 2012, p. 91-92).

Conquanto haja previsão da justiça social na Constituição Brasileira, o sistema capitalista vigente torna desiguais as relações empregatícias: de um lado, a classe dominante dos empregadores, que possuem seus direitos fundamentais assegurados; já de outro, a grande maioria dos trabalhadores, que, apesar de respaldados constitucionalmente pelas mesmas garantias fundamentais, têm, cada dia mais, seus direitos lesados, inclusive, com as tentativas de flexibilização das atividades laborais (HOBSBAWM, 1996, p. 50).

Como em um Estado Democrático de Direito não se concebe a flexibilização dos direitos fundamentais do homem, não se pode conceber, do mesmo modo, a flexibilização dos direitos sociais que lhe garantem ou que, ao menos, deveriam lhe garantir uma existência digna; aliás, uma flexibilização da dignidade do trabalhador, fato que não se faz nem moral, tampouco (e sobretudo) constitucionalmente, vez que vai de encontro a um pretenso regime de justiça social com fundamento no valor social do trabalho.

É impossível falar em trabalho sem mencionar seu principal protagonista - o homem; constitucionalmente, a vida está tutelada pelo princípio da dignidade da pessoa humana, em que todos estão protegidos por lei e ninguém poderá ser, arbitrariamente, provado de sua existência.

Comparato, claramente, relaciona a dignidade de cada indivíduo ao simples fato dele existir; portanto, independentemente de qualquer outro fator, basta à pessoa nascer para ser titular da dignidade humana como direito (COMPARATO, 2010, p. 45).

Nessa direção, constata-se que a dignidade acompanha todos os indivíduos desde sua origem. Por isso, importante destacar que, mesmo em época de flexibilização do Direito do Trabalho, cresce o movimento de valorização do seu princípio protetor como forma de realização do princípio da igualdade real entre os atores sociais partícipes da relação jurídica de trabalho e da 
dignidade da pessoa humana do trabalhador.

Relembrando as considerações históricas do direito laboral, a desembargadora mineira Alice Monteiro de Barros bem assevera que este ramo jurídico, desde os primórdios, irrompeu sob o império da máquina, como uma reação aos vícios da liberdade econômica e à exploração prematura do material humano, que aduzia a acidentes mecânicos do trabalho, baixos salários e excessivas jornadas, em que os principais lesados são os trabalhadores indo, diretamente, contra o princípio da dignidade da pessoa humana (BARROS, 1999, p. 09).

Ultimamente, porém, ante os avanços tecnológicos e as transformações da globalização na sociedade, os direitos e as garantias trabalhistas que devem ser preservados estão em discussão, sobretudo a manutenção da dignidade da pessoa humana do trabalhador, tendo em vista a importância desta garantia para propiciar a todos os seres humanos uma sociedade mais justa, com igualdade de oportunidades, para o seu pleno desenvolvimento físico e intelectual.

\subsection{Do direito à intimidade e à vida privada do trabalhador}

Etimologicamente, privacidade compreende o conjunto de informações acerca do indivíduo, as quais ele pode decidir manter sob seu controle ou comunicar a terceiros, da maneira como preferir; o direito à privacidade abrange o direito à intimidade, porém a Constituição Federal faz a distinção desses direitos (FERREIRA, 1986, p. 30).

Constitucionalmente, a intimidade alberga a vida particular do indivíduo, enquanto a privacidade consiste na proteção da vida exterior - atividades públicas, sociais, profissionais - e da vida interior - atividades junto à família, aos amigos, etc.; contudo, a violação tanto à intimidade quanto à vida privada é protegida e assegura ao lesado direito à indenização (BRASIL, 1988).

É ressaltada a importância do respeito desses direitos do indivíduo em todo e qualquer lugar, precipuamente, no meio ambiente de trabalho, onde, frequentemente, os empregadores ultrapassam os limites ao poder diretivo, infringindo, rigorosamente, os direitos à intimidade e à vida privada do empregado.

Mesmo que o poder diretivo possibilite ao empregador uma maior abrangência no local e nos horários de trabalho de seu empregado, por exemplo, no caso de revistas íntimas, ainda que, com o consentimento do empregado, a ação torna-se uma afronta direta aos princípios constitucionais (NUNES, 2011, p. 56).

A CLT já contém dispositivo neste sentido, conforme já citado, mas, qual o limite entre a revista moderada e a íntima? Dessa premissa, entende-se ser necessário utilizar não apenas os institutos em pauta, mas, também, o princípio da razoabilidade, que pode orientar o poder de controle do empregador, estabelecendo o bom senso como limite de seu poder diretivo e o respeito à dignidade do seu empregado/colaborador como meta dessa relação de trabalho.

$\mathrm{O}$ direito à intimidade e à vida privada elege um direito fundamental; portanto, quando atingir a pessoa do trabalhador o direito da personalidade deverá prevalecer. Ainda que o direito à intimidade e à vida privada não seja absoluto, são direitos fundamentais que devem ser sempre 
preservados, afinal todos direitos fundamentais devem ser tratados por sua unidade e harmonização.

A Consolidação das Leis do Trabalho é omissa a respeito dessa questão e encontra obstáculos nas reiteradas decisões judiciais, que vêm propiciando ocasiões de invasão da privacidade do operário porque relacionam violação da vida privada e da intimidade dos trabalhadores com o poder diretivo. Ocorre que não é a subordinação do empregado, muito menos a detenção de poder diretivo do empregador, que irão justificar a ineficácia da tutela à intimidade no local de trabalho (ROMITA, 2009, p. 83).

O conceito de poder diretivo do século XXI deve ser diverso daquele empregado na Idade Média, visto que o empregado não é mais o servo, muito menos o empresário: seu senhor. Sendo assim, essas garantias de liberdade individual e dignidade humana do trabalhador representam um espaço íntimo intransponível por intromissões de terceiros, principalmente do empregador.

Tendo em vista a não violação desses direitos resguardada constitucionalmente, em que o empregador jamais pode transpor a intimidade e a vida privada de seus funcionários, a questão da revista no ambiente de trabalho (seja pessoal ou íntima) é um exemplo de possível conflito oriundo do poder de direção do empregado em face da intimidade e privacidade do empregado.

Entretanto, como bem ressalta Maurício Godinho Delgado, a importância do valor social do trabalho, para a nossa sociedade, é um dos mais relevantes veículos de valorização do próprio ser humano, uma vez que a larga maioria dos indivíduos mantêm-se, na desigual sociedade capitalista, essencialmente, por meio de sua atividade laborativa (DELGADO, 2005, p. 167).

Assim, devido à extrema relevância do trabalho para a existência humana, a grande massa de trabalhadores está subordinada ao poder diretivo para garantia de seu emprego e como fruto desse poder empregatício sobrevêm as revistas realizadas pelos empregadores ou seus prepostos que, quando íntimas, são simplesmente proibidas, ferindo, diretamente, os direitos fundamentais à intimidade e à vida privada dos empregados.

Por óbvio que existem excepcionais situações em que o tipo de atividade empresarial impõe um maior controle sobre as entradas e saídas das empresas: indústrias fabricantes de drogas lícitas, de joias e de peças íntimas, por exemplo. Em tais casos, a revista deve ser a mais cuidadosa possível, equacionando o respeito ao indivíduo com o imperativo fiscalizatório (DUARTE; TUPINAMBÁ, 2002, p. 234). Saliente-se que o ideal é que a revista íntima aconteça, exclusivamente, na saída dos locais de trabalho, por meio de um sistema de delação automática e mediante acordo entre patrão e empregados.

Todavia, caso a opção do empregador for a colocação de câmeras de vídeo ou televisão, ressalta Marcelo Roberto Viana que tais meios fiscalizatórios devem estar vinculados aos limites impostos nos princípios constitucionais de personalidade dos empregados de direito à proteção da intimidade e privacidade (VIANA, 1996, p. 234). Importante destacar, além disso, que tais meios eletrônicos jamais podem ser instalados nos locais reservados e íntimos dos empregados, como vestiários, banheiros, refeitórios e dormitórios; sempre respeitando o princípio da razoabilidade, sem abuso do direito, caracterizado pelo excesso do poder fiscalizatório. 


\subsection{A revista íntima no meio ambiente de trabalho e a violação da dignidade da pessoa humana e dos direitos fundamentais}

Pelo escopo assinalado, a CF/88 assegura a todos cidadãos brasileiros ou estrangeiros os direitos fundamentais, também conhecidos como direitos humanos, direitos subjetivos públicos, direitos do homem, direitos individuais, liberdades fundamentais ou liberdades públicas; e com ênfase: o direito à intimidade e à vida privada do trabalhador e os direitos fundamentais, cuja finalidade está em proteger a dignidade humana em todas as suas dimensões (SARLET, 2012, p. $55)$.

Em plano posterior, ressalta-se, ainda, que tanto a análise dos direitos fundamentais quanto das garantias constitucionais é considerada relevante para a compreensão e complementação do tema - revista íntima e violação da dignidade da pessoa humana -, para proteção aos direitos da personalidade do empregado, mormente na fase de cumprimento de contrato de trabalho, haja vista que na maioria das vezes há abuso do poder diretivo durante as revistas íntimas realizadas pelos empregadores e seus prepostos, fatos esses que violam veementemente as garantias supramencionadas que jamais podem ser olvidadas, uma vez que, também ferem a dignidade da pessoa humana do trabalhador, que acima de tudo é um ser humano.

Tais revistas denominadas íntimas são aquelas praticadas em relação ao trabalhador ante qualquer ato de molestamento físico ou a coerção para se despir em ação capitaneada por funcionário ou encarregado da empresa, exigindo do empregado que exponha ou coloque à mostra seu corpo, ainda que de forma parcial.

Ocorre que, não existe respeito em determinar que um empregado fique nu, contra sua vontade, para a prática de revista, pois a exposição do corpo consiste na invasão da intimidade; mesmo quando não se imponha a nudez completa, se configura a invasão à intimidade do trabalhador (NUNES, 2011, p. 68).

Em sua maioria, essas revistas são diariamente efetuadas na pessoa do empregado e adentram na esfera de sua intimidade, em que a habitual explicitação de seu corpo já caracteriza invasão de sua intimidade e, por consequência, violação à sua dignidade humana.

Por isso, a legislação trabalhista já proíbe, expressamente, o empregador ou preposto (do sexo masculino) a praticar revistas íntimas nas empregadas ou funcionárias. Haja vista a garantia da privacidade e intimidade, tanto às mulheres quanto aos homens, o empregador ou preposto da empresa fica vedado de proceder à revista íntima: trata-se de uma garantia constitucional, por isso seu descumprimento acarreta em violação à dignidade humana do indivíduo (CABETTE, 2016). Ressalta-se que, a CLT, também, tem previsão sobre a proibição no artigo 373-A, VI, cujo dispositivo resta evidente esse impedimento legal em relação às revistas íntimas dos empregadores durante o contrato de trabalho em seus funcionários.

Nesse mesmo compasso, existem reiteradas decisões jurisprudenciais que consideram a revista íntima no local de trabalho uma violação do direito constitucional à intimidade, dado 
que tal conduta não encerra a necessidade do contato físico entre empregado e supervisor, sendo suficiente para conformação do ato abusivo a revista visual, em que o trabalhador é constrangido a exibir seu corpo nu, ou em roupas íntimas, não sendo atenuante, nesse caso, o fato de o supervisor ser do mesmo sexo do empregado (BRASIL, 2011).

Destarte, o contato visual já esculpe prática abusiva, segundo o entendimento do TST, por sujeitar o empregado à situação constrangedora, ofendendo sua honra, intimidade e dignidade ao ter que ficar apenas com roupas íntimas em frente de seu supervisor hierárquico.

Também são abusivas as práticas das revistas íntimas empresariais, quando inseridas na relação de emprego, pouco importando o consentimento do empregado. A prática é desqualificada pelo caráter de ser atentatória à dignidade do trabalhador. A modalidade de "revista íntima" forma o ápice da promoção do desrespeito ao trabalhador, levando o poder de direção do empregador às consequências mais agressivas ao patrimônio de seu funcionário (LIMA FILHO; PEREIRA, 2009, p. 29).

Nesta toada nota-se que a revolta causada nas revistas íntimas é inequívoca. Contudo a matéria é mais nevrálgica, afinal é preciso enfatizar que existem, ainda, as revistas não íntimas, também chamadas ilegítimas, antijurídicas e atentatórias aos direitos de intimidade pessoal. Em razão disso, também nesses casos, não se pode admitir uma renúncia válida do empregado na formalização do seu contrato de trabalho (SOUZA, 2008, p. 176).

Ressalta-se ainda ser indiferente que essas revistas, cujos teores são pessoais, mesmo que ocorram diante de clientes ou demais funcionários ou que sejam realizadas em locais de absoluto resguardo; a incolumidade física e moral dos trabalhadores não está na relativização no curso do contrato de trabalho (NUNES, 2011, p. 119).

Aliás, inseridos em uma realidade fraqueada por um horizonte repleto de recursos tecnológicos e de outras formas que facultam descortinar a existência de produtos ou pertenças da empresa junto ao empregado, sequer há a necessidade de recorrer às revistas íntimas. Isso sem contar a possibilidade de se evitar a revista íntima recorrendo-se ao uso de vestimentas especiais; por exemplo, enquanto o empregado está no trabalho fazer uso de macacão sem bolso (ROMITA, 2005, p. 83).

Existem diversos meios para que as revistas íntimas sejam evitadas, respeitando, em primeiro lugar, os direitos fundamentais e os princípios constitucionais. Reitere-se: não há revista íntima razoável. Já que o ato em si constitui abuso de direito e, diante do regramento constitucional, é ilícito. O direito de propriedade não se estende a ponto de permitir ao empregador dispor a intimidade de seus empregados, submetendo-os, cruelmente, a humilhações, às quais se curvam pela necessidade de conservação do emprego.

Não é legítimo tolerar-se a recusa a valor tão básico, cuja reiteração, por certo, redunda em rigorosa modificação do espírito e em irrecusável sofrimento para o trabalhador. Pergunta-se como reagiriam empregador, seus prepostos e, ainda, aqueles que firmam tal comportamento acaso submetidos a diárias revistas íntimas. Não se crê que, então, sustentassem-nas com tal vigor. São inapreensíveis por outrem os direitos pessoais à preservação da dignidade, intimidade, privacidade 
e honra. Infligindo dano moral, obriga-se o empregador à indenização correspondente (TST, 2017).

Dessa forma, a CLT admite a revista dos empregadores e seus prepostos em todos seus funcionários, desde que não seja abusiva, muitas vezes, sob os argumentos de que o objeto da própria atividade empresarial permite a vistoria no local de acesso à saída dos trabalhadores. Contudo, a revista íntima, de qualquer maneira, é invasiva e pode ser realizadas tão somente por meio de equipamentos eletrônicos, tais como scanners, aparelhos de Raio X e detectores diversos, a fim de se evitarem constrangimentos desnecessários e ofensas à dignidade da pessoa humana.

\section{A INTELIGÊNCIA ARTIFICIAL E OS ASPECTOS TECNOLÓGICOS DA REVISTA ÍNTIMA NO MEIO AMBIENTE DE TRABALHO}

Em relação à revista dos funcionários ao entrar e sair do seu local de trabalho, vale esclarecer que essa matéria sofreu profundo avanço desde a Constituição Brasileira de 1988. Já que se trata de um procedimento empresarial decorrente do poder diretivo do empregador, cuja finalidade é salvaguardar o patrimônio da empresa e a segurança dos empregados.

No ambiente de trabalho, essa revista íntima tem sido um terreno de conflitos oriundo do poder de direção do empregador versus a intimidade e privacidade do empregado. E isso, invariavelmente, provoca inquietações, tais como: Ao empregador, é permitido, ao fiscalizar seus empregados, proceder a revistas íntimas? Essa "revista íntima" refere-se apenas ao corpo do trabalhador ou também a seus pertences? (ROMITA, 2005, p. 48).

Possivelmente a maior dificuldade para se atingir à plausibilidade está na ausência de uma linha exata e distinta que estabeleça onde começa e onde termina o poder de subordinação do empregado; nem sempre há uma única resposta a estas perguntas, visto ser quase impossível distinguir tal poder diante das inovações tecnológicas de trabalho e dos novos meios de informação.

Ocorre que, o desenvolvimento da inteligência artificial e a presença das máquinas no meio ambiente laboral em ascendência, certamente, proporcionarão o equilíbrio necessário ao poder diretivo do empregador, tornando, futuramente, essas revistas íntimas possivelmente mecanizadas em sua totalidade, evitando que os empregados sejam submetidos a contatos físicos involuntários e a constrangimentos com seu superior hierárquico ou preposto que o revista.

A exemplo disso, destaca-se os aeroportos internacionais em que, as revistas são realizadas com eficiência por meio de robôs programados através das novas tecnologias (AI), oportunidade favorece duplamente tanto a prestadora de serviços quanto usuário, uma vez que, a companhia área pode empregar outros funcionários em funções diversas daquelas em que deveriam revistar os passageiros diariamente, na mesma proporção em que, o usuário também sente-se ainda mais confortável com a ausência de contato humano na revista de seus pertences pessoais, especialmente, contato físico, haja vista que a máquina já registra todos os dados necessários para a segurança dos aeroportos e de todos os passageiros que adentrarem naquele estabelecimento comercial. Este tipo de revista, bem impessoal, poderia ser empregada nos ambientes de trabalho, sem o desgaste que ocasiona uma revista com através do contato físico. (RIBEIRO, 2017). 
Desse modo, atualmente, além de diversas funções antes exercidas pelos empregadores ou seus prepostos já caminharem para a automatização crescente; nada impede, que, no futuro, quiçá, robôs estejam fazendo essas revistas nos empregados, por meio de chips e sensores de memória, mundialmente, bem como, avançar cada vez mais o aparato tecnológico para substituir as revistas física, por outras mais avançadas.

A grande vantagem em conciliar a tecnologia com as atividades laborais, no caso das revistas íntimas, está na facilidade em programar uma máquina para executar tarefas rotineiras, como ler chips ou, até mesmo, monitorar os empregados com um laser; fiscalizando-os. Ademais, estatisticamente, essas tarefas automatizadas por tecnologias gastam apenas metade do tempo se comparadas ao desnecessário intervalo gasto pelos empregadores com essas revistas (CASSIOLATO, 2000, p. 237).

A abertura à tecnologia já demonstra benefícios em relação à automatização dos postos de trabalho, auxiliando ambas as partes da relação empregatícia: o empregador terá seu poder diretivo equilibrado, com menos risco de errar e aproveitando, ainda mais, seu espaço temporal, com o auxílio das máquinas/robôs; enquanto os trabalhadores não serão, frequentemente, submetidos a constrangimentos desnecessários respeitando-se, especialmente, o princípio da dignidade da pessoa humana de todos os empregados do estabelecimento comercial.

Não obstante, a tecnologia provê à sociedade meios mais confortáveis de viver, e extingue, de certo modo, a penosidade do trabalho, e isso pode causar inadequações na ordem social. É evidente que os avanços tecnológicos diminuirão o revés do trabalho, mas também podem acabar reduzindo postos de trabalho e até eliminando alguns tipos de serviços manuais. Contudo, para a sociedade, não será um mal, já que a automação traz para os consumidores e para a economia um acréscimo da rede de proteção social: seguro-desemprego e benefícios previdenciários (MAIOR, 2003, p. 4).

Por esta razão, a inteligência artificial é apontada como uma solução prática, que caminha ao lado da evolução do Direito Laboral, singularmente no procedimento das revistas realizadas pelos empregadores ou seus prepostos em seus funcionários, em que a automação poderá colaborar, precisamente, tanto na economia do tempo gasto, com o melhor aproveitamento da jornada de trabalho, quanto na ausência de constrangimento dos empregados, dada a impessoalidade das máquinas, quando do monitoramento dessas revistas.

\section{CONCLUSÕES}

Ao analisar os direitos fundamentais do homem e os direitos sociais que lhe são próprios, depreende-se que o conjunto desses direitos são imprescindíveis à concretização da própria dignidade da pessoa humana.

Os direitos sociais constituem, categoricamente, os novos direitos fundamentais do homem à proporção que concebem um meio positivo que reconhece o direito ao trabalho como condição precípua no caminho da efetividade da existência digna de todos os brasileiros constitucionalmente 
previstos.

A reiteração específica da dignidade da pessoa humana deve ser preservada, principalmente a manutenção da dignidade do trabalhador, concatenando a importância desta garantia para propiciar a todos os seres humanos uma sociedade mais justa, com igualdades de oportunidades, para o seu pleno desenvolvimento físico e intelectual.

Esse instituto opera enquanto regra clara que tanto a intimidade quanto a vida privada de todos os empregados devem ser respeitadas no âmbito do estabelecimento empresarial, durante a vigência de todo o contrato de trabalho. Neste estudo, o enfoque esteve nas revistas íntimas dos empregadores, equilibrando-se o poder diretivo da classe dominante em face dos trabalhadores, que são a minoria e devem ter sua dignidade respeitada em atenção ao princípio constitucionalmente previsto.

Para que tais revistas não se tornem invasivas, o presente estudo sugere como ideal que a revista íntima fosse realizada, exclusivamente, na saída dos locais de trabalho, por meio de um sistema de delação automática e mediante acordo entre patrão e empregados, para celebrarem, com igualdade, os direitos de seus empregadores, precavendo-se de atingir os direitos da personalidade, especialmente a dignidade da pessoa humana.

Para tanto, a inteligência artificial é apontada como uma solução prática, que caminha ao lado da evolução do Direito Trabalhista, singularmente no procedimento das revistas realizadas pelos empregadores ou seus prepostos em seus funcionários, em que a automação poderá colaborar, precisamente, tanto na economia do tempo gasto, com o melhor aproveitamento da jornada de trabalho, quanto na ausência de constrangimento dos empregados, dada a impessoalidade das máquinas, quando do monitoramento dessas revistas.

Infere-se que, assim como em experiências precedentes, existem reiteradas decisões jurisprudenciais que consideram a revista íntima no local de trabalho uma violação do direito constitucional à intimidade porque semelhante ação não pressupõe, necessariamente, o contato físico entre empregado e supervisor, sendo suficiente para qualificação do ato abusivo a revista visual, em que o trabalhador é compelido a exibir seu corpo nu, ou em roupas íntimas, não sendo atenuante, nesse caso, o fato de o supervisor ser do mesmo sexo do empregado.

Em derradeiro, constata-se, ainda, que todo trabalhador deve ter sua dignidade humana respeitada durante o contrato de trabalho, afinal o empregado constrói sua identidade no meio ambiente laboral e isso deve ser preservado, uma vez que traduz o princípio basilar da legislação trabalhista.

\section{REFERÊNCIAS}

ALEXY, Robert. Teoria dos Direitos Fundamentais. Tradução de Virgílio Afonso da Silva. São Paulo: Malheiros, 2008. Título original: Theorie der Grundrechte.

BARROS, Alice Monteiro. Flexibilização e garantias mínimas. Revista Trabalho \& Doutrina, São Paulo, v. 20, 1999. 
BRASIL. [Constituição (1988)]. Constituição da República Federativa do Brasil de 1988. Brasília, DF: Senado Federal, 1988.

BRASIL, Tribunal Superior do Trabalho, Processo No AIRR-1001517-44.2017.5.02.0067. cfr. E-RR 85400-89.2004.5.02.0024, Rel. Des. Conv. Sebastião Geraldo de Oliveira, SBDI-1, DEJT de 09/01/12; AGAIRR 1495-73.2012.5.02.0068, Rel. Min. Walmir Oliveira da Costa, $1^{\text {a }}$ Turma, DEJT de 19/02/16; AIRR 46-66.2011.5.02.0084, Rel. Min. José Roberto Freire Pimenta, $2^{\mathrm{a}}$ Turma, DEJT de 01/04/16; AIRR 1137-11.2014.5.02.0401, Rel. Min. Alberto Luiz Bresciani, $3^{\mathrm{a}}$ Turma, DEJT de 01/04/16; AG-AIRR 343-82.2013.5.02.0317, Rel. Min. João Oreste Dalazen, 4a Turma, DEJT de 11/03/16; AG-AIRR 652-06.2013.5.02.0317, Rel. Min. Caputo Bastos, $5^{\mathrm{a}}$ Turma, DEJT de 08/04/16; AIRR 3068-70.2011.5.02.0040, Rel. Min. Kátia Magalhaes Arruda, 6 a Turma, DEJT 27/11/15; AIRR 68600-91.2009.5.02.0482, Rel. Min. Vieira de Mello Filho, $7^{\text {a }}$ Turma, DEJT de 08/04/16; AIRR 1647-23.2014.5.02.0078, Rel. Min. Maria Cristina Peduzzi, $8^{\mathrm{a}}$ Turma, DEJT de $08 / 04 / 16$.

CABETTE, Eduardo Luiz Santos. Proibição de revistas íntimas: comentários à Lei $\mathrm{n}^{\mathrm{o}}$ 13.271/2016. Revista Jus Navigandi, Teresina, ano 21, n. 4681, 25 abr. 2016. Disponível em: https://jus.com.br/artigos/48483. Acesso em: 28 set. 2018.

CASSIOLATO, José Eduardo; LASTRES, Helena Maria. Sistemas de inovação: políticas e perspectivas. Revista Parcerias Estratégicas, Brasília, v. 5, n. 8, 2000.

COMPARATO, Fabio Konder. A afirmação histórica dos direitos humanos. 7. ed. São Paulo: Saraiva, 2010.

DELGADO, Maurício Godinho. Princípios constitucionais do trabalho. Revista de Direito do Trabalho, São Paulo, ano 31, n. 117, 2005.

DUARTE, Juliana Bracks; TUPINAMBÁ, Carolina. Direito à intimidade do empregado e poder diretivo do empregador. Revista de Direito do Trabalho, São Paulo, v. 28, n. 105, 2002.

FERREIRA, Aurélio B. Hollanda. Novo dicionário da língua portuguesa. 2. ed. Rio de Janeiro: Nova Fronteira, 1986.

HOBSBAWM, Eric J. A era do capital 1848-1875. 9. ed. São Paulo: Paz e Terra, 1996.

KANT, Immanuel. Crítica da razão pura. São Paulo: Abril Cultural, 1974.

LIMA FILHO, Francisco das Chagas; PEREIRA, Simone. O assédio moral nas relações laborais e a tutela da dignidade humana do trabalhador. São Paulo: LTr, 2009.

MAIOR, Jorge Luiz Souto. Do direito à desconexão do trabalho. Revista do Tribunal Regional do Trabalho da $15^{a}$ Região, Campinas, n. 23, p. 296-313, jul./dez. 2003. Disponível em: egov. ufsc.br. Acesso em: 8 nov. 2018.

NUNES, Rosana Marques. A revista íntima como cláusula restritiva de direitos fundamentais no direito do trabalho. São Paulo: LTr, 2011.

RIBEIRO, Davi. Escaneamento facial e robôs integram aeroportos do futuro. Folha de São Paulo Online, São Paulo, 31 ago. 2017. Disponível em: https:/www1.folha.uol.com.br/ 
turismo/2017/08/1914472-escaneamento-facial-e-robos-integram-aeroportos-do-futuro.shtml. Acesso em: 19 fev. 2020.

ROMITA, Arion Sayão. Direitos fundamentais nas relações de trabalho. 5. ed. São Paulo: LTr, 2005.

SARLET, Ingo Wolfgang. Dignidade da pessoa humana e direitos fundamentais na

Constituição Federal de 1988. Porto Alegre: Livraria do Advogado, 2012.

SILVA, José Afonso. Curso de direito constitucional positivo. 30. ed. São Paulo: Malheiros, 2007.

SOUZA, Rodrigo Trindade. Função social do contrato de emprego. São Paulo: LTr, 2008.

VIANA, Márcio Túlio. Direito de resistência. São Paulo: LTr, 1996.

Como Citar: MARQUES, Ana Paula Baptista. DA SILVA, Leda Maria Messias. A revista intima no meio ambiente de trabalho e a violação da dignidade da pessoa humana à luz da inteligência artificial e dos aspectos tecnológicos.Scientia Iuris, Londrina, v.24, n.1, p. 135-148, março 2020. DOI 10.5433/21788189.2020v24n1p135. ISSN 2178-8189.

Recebido em 07/05/2019

Aprovado em 20/02/2020 